\title{
Simulation Approach for Active PFC Power Converters with DSP Control Scheme
}

$\begin{array}{llll}\text { Student Member } & \text { Ulhaqsyed } & \text { MOBIN } & \text { (Yamaguchi University) } \\ \text { Member } & \text { Hiroshi } & \text { TAKANO } & \text { (Hitachi Medical Co.) } \\ \text { Member } & \text { Mutsuo } & \text { NAKAOKA } & \text { (Yamaguchi University) }\end{array}$

This paper describes practical application examples of digital signal processor (DSP) controlled single-phase and three-phase power factor correction (PFC) converter systems using a new efficient simulation approach discussed herein. In this method, software code for control function simulation is also practically applicable to software of a DSP based active PFC power conversion conditioning and processing systems. This power electronic circuit simulation technique is based on a circuit equation modeled by substituting switch modulated resistors in place of all the active and/or passive power switches incorporated in the bridge legs of power converter circuit, one state-vector equation described by state-variables for inductors and capacitors, and an algebraic computation method to transform the matrices of the circuit equation into matrices of the state vector equation. Furthermore, the effectiveness of a DSP controlled PWM strategies of voltage-fed single and three phase PFC converter systems are confirmed and performance evaluations on the basis of computer-aided simulation results are illustrated and discussed together with experimental results.

Keywords: Power electronics, Circuit simulation, Switch modulated resistor, Power factor correction, Digital signal processor.

\section{INTRODUCTION}

In recent years, a variety of simulation techniques has been developed for switch-mode power converter circuits and systems using power semiconductor devices. The circuit designers who use simulation approaches have more flexibility in analysis and design process and can investigate more options in performance evaluations.

Some features such as high frequency PWM, PFM, PAM and PDM schemes for control of switching power semiconductor devices, complexity due to the digital and analog control based circuitry, non-linearity of power semiconductor devices and circuit topological characteristics, resonant and quasi-resonant configurations, continuous and discontinuous current mode operations, make efficient and highly precise computer simulation of power conversion circuits and systems very unique and challenging.

Some problems encountered frequently in power electronic conversion circuit and system simulation are as follows,

(i) Inefficient simulation time due to presence of a large number of high frequency power switching devices incorporated in the power converters.

(ii) Convergence problem becomes prominent if models of power switching device and circuit component having many parameters are used.

(iii) In case of power electronic circuit simulation, modeling and analysis of its related digital control scheme are more difficult.

To overcome problems mentioned above, the authors have proposed a simulation approach, in which switch modulated resistor circuit simulates all the active and/or passive switching power devices in the power electronic conversion system. Throughout the circuit analysis, the mathematical computations are based upon simple algebraic manipulations of state vector matrices without involving complicated Laplace transformed equations or differential equations. The authors can also perform this state equation based simulation using general purpose simulation software platform like MATLAB/ SIMULINK. However, using a general-purpose platform introduces a disadvantage of slow and inefficient execution of simulation.

In the proposed circuit simulation method treated here, the mathematical calculation steps required are effectively reduced as compared with tableau method ${ }^{(1)}$ because the computation is to be repeated for one state equation matrix. The circuit characteristics of state variables related to inductors and capacitors can be computed more efficiently from the state equation as explained in the references (2) (3) (4) (5).

In simulation, if a power converter circuit has several or many operating modes, then it is difficult to choose the appropriate state equations for each operating mode. In several operation mode cases, convergence errors are likely to occur more. In proposed simulation technique, the switch mode transitions of power converters are programmed with simple $\mathrm{C}++$ programming statements ("if" and "else if" style) to minimize convergence errors.

Circuit modeling can be complex in the case of many circuit parameters per device or can be simple in the case of less parameters per device. For calculation of system behavior, harmonic components, power factor, and to achieve fast simulation speed, the simplest behavior or less complex macroscopic model of switching power device is required. The functioning of a power converter is based upon active and passive switching operation. Therefore, only switching behavior need to be modeled. In simulation approach proposed here, power semiconductor switches such as MOSFETs, IGBTs and SITs are modeled as simple ON/OFF resistance switches $\left(R_{o n}=10 \mathrm{~m} \Omega\right.$ and $R_{\text {off }}=100 \mathrm{k} \Omega$ ) with a short dead time present between switching transitions.

The choice of either fixed or variable time step has a major effect on total simulation time. Simulation programs designed for all modes case use variable time step, because the non-linear nature of the power electronic circuit requires extremely small time step in some cases whereas relatively large time steps in other cases. However, choosing a small time step does not 
necessarily yields more accurate results. In the proposed simulation technique, a fixed simulation time step is synchronized with switching instant of active and/or passive power switching device. Switch state condition is checked in accordance with each time increment and the state-variables, switch currents and voltages are calculated at the same time. This ensures minimum convergence errors.

Control algorithm and its related parameter values used in proposed simulation can be incorporated in the software of a DSP controlled power conversion system. Hence, the proposed simulation approach simplifies the practical analysis and design of DSP controlled power converter circuits and systems. Making use of $\mathrm{C}$-language computer source code ensures portability of the simulation program treated here among different operating systems. Therefore, it can be used on UNIX, Macintosh and PCs alike.

In section 2, major steps of simulation program are described by an application example of a DSP controlled active singlephase PFC converter. Section 3 illustrates another application example of the proposed simulation technique to a DSP controlled active three-phase PFC converter. Section 4 discusses DSP control scheme of both types of active PFC converters. Section 5 is concerned with comparison of simulation with experimentally measured results.

\section{Simulation of ACtive Single-Phase AC-DC CONVERTER SYSTEM}

2.1 Circuit model description Figure 1 shows an example of active single-phase voltage-fed AC-DC power converter system under PFC conversion conditioning and processing. Detecting the signals of input current $i_{L u}$ and output voltage $e_{c o}$ the DSP control scheme produces PWM gate signals for modulating the pulse voltages across IGBTs, $S_{1}$ and $S_{2}$. A unity power factor in utility power side can be achieved under sinewave current shaping processing along with a regulated DC output voltage. Output of this power converter is regulated by DSP based control processing scheme.

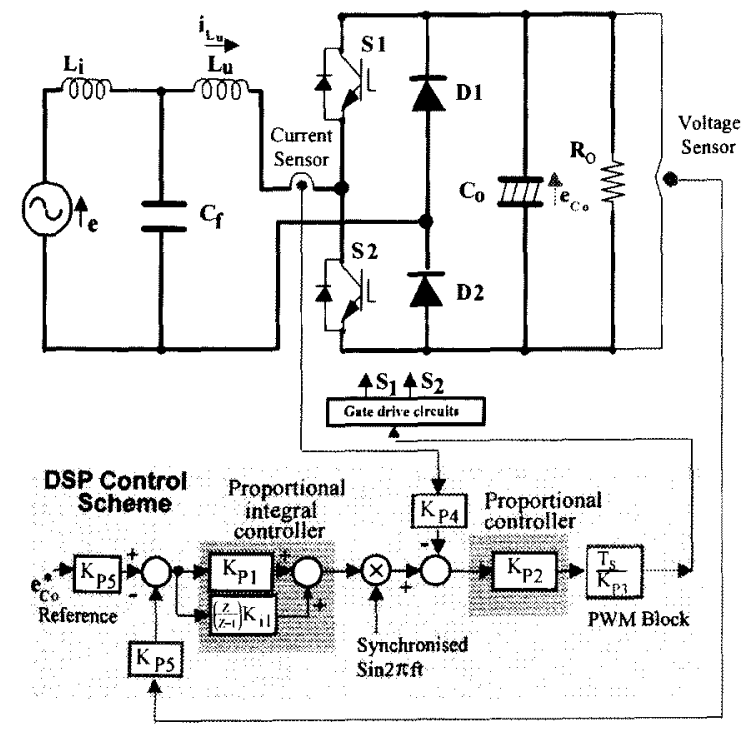

Fig.1 Single phase PFC converter circuit with DSP control scheme

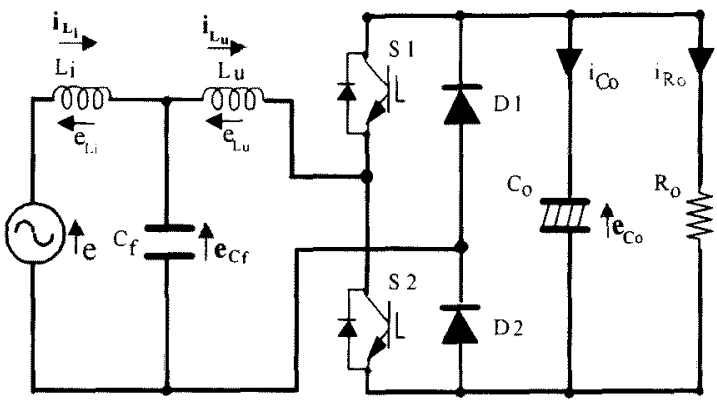

(a) Power converter circuit

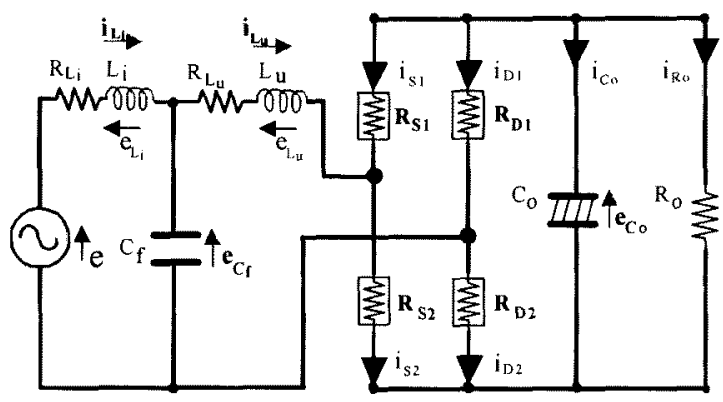

(b) Power converter circuit using switch modulated resistor circuit model

Fig.2 Formulation of simulation circuit model for singlephase PFC converter system

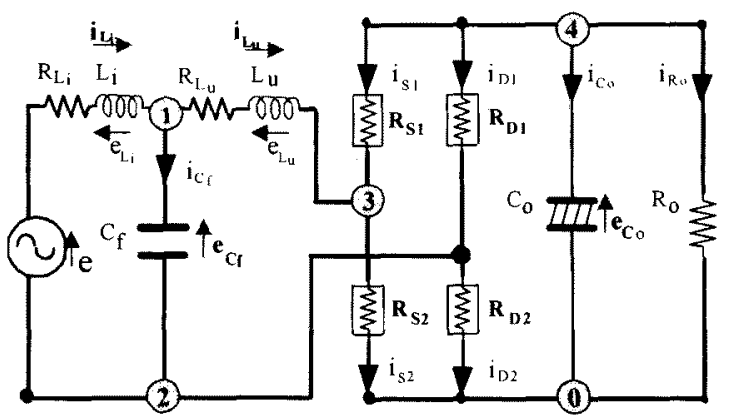

(a) Node diagram for $\mathrm{KCL}, \quad \mathrm{O}=$ Node

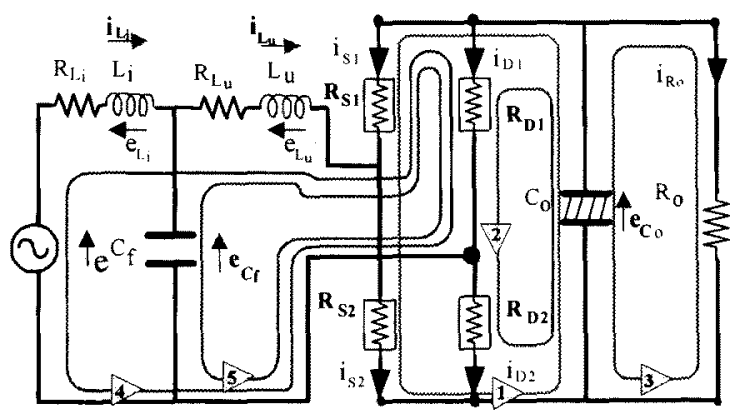

(b) Loop diagram for $\mathrm{KVL}, \quad>=$ Loop

Fig.3 Kirchoff's node and loop diagrams for circuit analysis 


\begin{tabular}{|c|c|}
\hline Node 1 & $i_{L u}-i_{L i}=-i_{C r}$ \\
\hline Node 2 & $\mathrm{i}_{\mathrm{Li}}=\mathrm{i}_{\mathrm{Cr}}+\mathrm{i}_{\mathrm{D} 1}-\mathrm{i}_{\mathrm{D} 2}$ \\
\hline Node 3 & $\mathrm{i}_{\mathrm{LB}}=-\mathrm{i}_{\mathrm{S} 1}+\mathrm{i}_{\mathrm{S} 2}$ \\
\hline Node 4 & $0=i_{S I}+i_{D I}+i_{C o}+i_{R_{0}}$ \\
\hline Loop 1 & $e_{C o}=R_{S 1 \cdot} i_{S 1}+R_{S 2 \cdot} i_{S 2}$ \\
\hline Loop 2 & $\mathrm{e}_{\mathrm{Co}}=\mathrm{R}_{\mathrm{D} 1} \cdot \mathrm{i}_{\mathrm{D} 1}+\mathrm{R}_{\mathrm{D} 2 \cdot \mathrm{i}_{\mathrm{D} 2}}$ \\
\hline Loop 3 & $e_{C_{0}}=R_{0} \cdot i_{R_{0}}$ \\
\hline Loop 4 & $-e+R_{L i} \cdot i_{L i}+R_{L u} \cdot i_{L u}=-e_{L i}-e_{L u}+R_{S I} \cdot i_{S I}-R_{D 1} \cdot i_{D 1}$ \\
\hline Loop 5 & $-e_{C H}+R_{L u} \cdot i_{L u}=-e_{L u}+R_{S 1} \cdot i_{S 1}-R_{D 1} \cdot i_{D I}$ \\
\hline
\end{tabular}

2.2 Formulation of circuit equation Figure 2 illustrates the circuit simulation model. $S_{1}$ and $S_{2}$ represent the active IGBT power switches as $R_{S 1}$ and $R_{S 2}$. On the other hand, $D_{1}$ and $D_{2}$ represent the passive diodes as $R_{D 1}$ and $R_{D 2}$. On-state and offstate of $R_{S 1}, R_{S 2}, R_{D 1}$ and $R_{D 2}$ are considered as an ideal switching condition with $R_{\text {on }}=10 \mathrm{~m} \Omega$ and $R_{\text {off }}=100 \mathrm{k} \Omega$. Applying the Kirchoff's laws; KVL and KCL to the circuit network, node and loop circuit diagrams are derived as indicated in Fig.3. From node and loop diagrams, Kirchoff's equations are obtained in Table1. The state variables are voltages $e_{C f}$ and $e_{C_{0}}$ across the capacitors and the currents $i_{L i}$ and $i_{L u}$ through the inductors. Input variable is $\mathbf{u}(t)$. Relation between matrices $\mathbf{S}(t), \mathbf{N}(t)$ and $\mathbf{R}$ are obtained from Table 1 in circuit equation form as follows,

$$
\begin{aligned}
& \mathbf{S}(t)=\mathbf{R} \cdot \mathbf{N}(t) \\
& \mathbf{N}(t)=\mathbf{R}^{-1} \cdot \mathbf{S}(t) \\
& \mathbf{u}(t)=e=E_{m} \sin 2 \pi f t
\end{aligned}
$$

where, $\mathrm{E}_{\mathrm{m}}=\sqrt{2} \mathrm{E} . \mathbf{R}$ is called resistance matrix (9x9 in this case) determined by the switch modulated resistors in the circuit model. Non-state variable terms are arranged in $N(t)$ circuit equation matrix, whereas state variable terms in $\mathbf{S}(\mathrm{t})$ circuit equation matrix.

$\mathbf{s}(t)=\left(\begin{array}{c}\mathrm{i}_{\mathrm{Lu}}-\mathrm{i}_{\mathrm{i} i} \\ \mathrm{i}_{\mathrm{Lu}} \\ 0 \\ \mathrm{e}_{\mathrm{Co}} \\ \mathrm{e}_{\mathrm{Co}} \\ \mathrm{e}_{\mathrm{Co}} \\ -\mathrm{e}+\mathrm{R}_{\mathrm{Li}} \cdot \mathrm{i}_{\mathrm{Li}}+\mathrm{R}_{\mathrm{Lu}} \cdot \mathrm{i}_{\mathrm{Lu}} \\ -\mathrm{e}_{\mathrm{Cr}}+\mathrm{R}_{\mathrm{Lu}} \cdot \mathrm{i}_{\mathrm{Lu}}\end{array}\right)$

$\mathbf{N}(t)=\left(\begin{array}{lllllllll}i_{C f} & i_{S 1} & i_{S 2} & i_{D 1} & i_{D 2} & i_{C O} & i_{R_{O}} & e_{L i} & e_{L U}\end{array}\right)^{\gamma}$

$\mathbf{R}=\left(\begin{array}{ccccccccc}-1 & 0 & 0 & 0 & 0 & 0 & 0 & 0 & 0 \\ 1 & 0 & 0 & 1 & -1 & 0 & 0 & 0 & 0 \\ 0 & -1 & 1 & 0 & 0 & 0 & 0 & 0 & 0 \\ 0 & 1 & 0 & 1 & 0 & 1 & 1 & 0 & 0 \\ 0 & \mathrm{R}_{\mathrm{S} 1} & \mathrm{R}_{\mathrm{S} 2} & 0 & 0 & 0 & 0 & 0 & 0 \\ 0 & 0 & 0 & \mathrm{R}_{\mathrm{D} 1} & \mathrm{R}_{\mathrm{D} 2} & 0 & 0 & 0 & 0 \\ 0 & 0 & 0 & 0 & 0 & 0 & \mathrm{R}_{0} & 0 & 0 \\ 0 & \mathrm{R}_{\mathrm{S} 1} & 0 & -\mathrm{R}_{\mathrm{D} 1} & 0 & 0 & 0 & -1 & -1 \\ 0 & \mathrm{R}_{\mathrm{S} 1} & 0 & -\mathrm{R}_{\mathrm{D} 1} & 0 & 0 & 0 & 0 & -1\end{array}\right)$

(6)

$\mathbf{R}^{-1}=\left(\begin{array}{cccc}a_{1,1} & \ldots & \ldots & a_{1,9} \\ \ldots & \ldots & \ldots & \ldots \\ \ldots & \cdots & \ldots & \ldots \\ a_{9,1} & \ldots & \ldots & a_{9,9}\end{array}\right)$ where, $\quad a_{i, j}=\frac{\text { adjoint } R_{i, j}}{|R|} \quad(i=1,2,3 \ldots \ldots .9)$ and $(j=1,2,3, \ldots \ldots 9)$

2.3 Formulation of state equation The canonical or original form of the state vector equation is as follows,

$$
\frac{d}{d t} \mathbf{x}(t)=\mathbf{A} \cdot \mathbf{x}(\mathrm{t})+\mathbf{B} \cdot \mathbf{u}(\mathrm{t})
$$

where, $\mathbf{x}(\mathrm{t})$ is a state vector, $\mathbf{A}$ and $\mathbf{B}$ are the system matrices, $\mathbf{u}(\mathrm{t})$ is a system input vector. The state vector $\mathbf{x}(t)$ containing state variables: $e_{C f}$ and $e_{C o}$ for the capacitors, $i_{L i}$ and $i_{L u}$ for the inductors is defined as,

$$
\mathbf{x}(\mathrm{t})=\left(\begin{array}{llll}
\mathrm{e}_{\mathrm{Cf}} & \mathrm{e}_{\mathrm{CO}} & \mathrm{i}_{\mathrm{Li}} & \mathrm{i}_{\mathrm{Lu}}
\end{array}\right)^{T}
$$

Taking derivative of the state vector $\mathbf{x}(\mathbf{t})$, we get

$$
\frac{\mathrm{d}}{\mathrm{dt}}\left(\begin{array}{c}
\mathrm{e}_{\mathrm{Cf}} \\
\mathrm{e}_{\mathrm{Co}} \\
\mathrm{i}_{\mathrm{Li}} \\
\mathrm{i}_{\mathrm{Lu}}
\end{array}\right)=\left(\begin{array}{cccc}
1 / \mathrm{C}_{\mathrm{f}} & 0 & 0 & 0 \\
0 & 1 / \mathrm{C}_{\mathrm{o}} & 0 & 0 \\
0 & 0 & 1 / \mathrm{L}_{\mathrm{i}} & 0 \\
0 & 0 & 0 & 1 / \mathrm{L}_{\mathrm{u}}
\end{array}\right)\left(\begin{array}{c}
\mathrm{i}_{\mathrm{Cf}} \\
\mathrm{i}_{\mathrm{Co}} \\
\mathrm{e}_{\mathrm{Li}} \\
\mathrm{e}_{\mathrm{Lu}}
\end{array}\right)
$$

The right-hand side of eq.(10) is identical with the left-hand side of the state vector equation (8). In this way, $x(t)$ and $\frac{d}{d t} x(t)$ terms of state vector equation (8) are formulated. Next, the remaining two terms $\mathbf{A}$ and $\mathbf{B}$ are calculated from transformation of circuit equation matrices to the state equation matrices. Finally, arriving at the exact numerical solution of the state equation (8).

2.4 Transformation of circuit equation matrices to state equation matrices $S(t)$ in circuit equation (1) can also be expressed in state equation form by relating two new terms $\mathbf{K}_{\mathbf{x}}$ and $\mathbf{K}_{\mathbf{u}}$ to system input vector $\mathbf{u}(\mathrm{t})$ and state vector $\mathbf{x}(\mathrm{t})$ as,

$$
F(t)=\mathbf{K}_{\mathbf{x}} \cdot \mathbf{x}(t)+\mathbf{K}_{\mathbf{u}} \cdot \mathbf{u}(\mathrm{t})
$$

$$
\mathbf{K}_{\mathbf{x}}=\left(\begin{array}{rrrrrrrrr}
0 & 0 & 0 & 0 & 0 & 0 & 0 & 0 & -1 \\
0 & 0 & 0 & 0 & 1 & 1 & 1 & 0 & 0 \\
-1 & 1 & 0 & 0 & 0 & 0 & 0 & \mathrm{R}_{\mathrm{Li}} & 0 \\
1 & 0 & 1 & 0 & 0 & 0 & 0 & \mathrm{R}_{\mathrm{Lu}} & \mathrm{R}_{\mathrm{Lu}}
\end{array}\right)^{T}
$$

$$
\mathbf{K}_{\mathbf{u}}=\left(\begin{array}{lllllllll}
0 & 0 & 0 & 0 & 0 & 0 & 0 & -1 & 0
\end{array}\right)^{r}(13)
$$

$\mathbf{N}(\mathrm{t})$ in circuit equation (2) can also be represented in state equation form by substituting the right-hand side of $F(t)$ from eq. (11) in eq.(2) as,

$$
\begin{aligned}
& \mathbf{G}(\mathrm{t})=\mathbf{R}^{-1} \cdot \mathbf{F}(\mathrm{t})=\mathbf{R}^{-1} \cdot\left(\mathbf{K}_{\mathbf{x}} \cdot \mathbf{x}(\mathrm{t})+\mathbf{K}_{\mathbf{u}} \cdot \mathbf{u}(\mathrm{t})\right) \\
& \mathbf{G}(\mathrm{t})=\left(\mathbf{R}^{-1} \cdot \mathbf{K}_{\mathbf{x}}\right) \mathbf{x}(\mathrm{t})+\left(\mathbf{R}^{-1} \cdot \mathbf{K}_{\mathbf{u}}\right) \mathbf{u}(\mathrm{t})
\end{aligned}
$$

Observing $\mathrm{i}_{\mathrm{Cf}}, \mathrm{i}_{\mathrm{C}_{0}}, \mathrm{e}_{\mathrm{L},}, \mathrm{e}_{\mathrm{Lu}}$ in eq.(10), $\mathbf{R}^{*}$ is formed by selecting four rows from $R^{-1}$ corresponding to row numbers $1,6,8$ and 9 of $N(t)$ in eq. $(5)$ for $i_{C f}, i_{C o}, e_{L i}$ and $e_{L u}$

$$
\mathbf{R}^{*}=\left(\begin{array}{lllllll}
a_{1.1} & a_{1.2} & \cdots & \cdots & \cdots & a_{1.8} & a_{1.9} \\
a_{6.1} & a_{6.2} & \cdots & \cdots & \cdots & a_{6.8} & a_{6,9} \\
a_{8.1} & a_{8.2} & \cdots & \cdots & \cdots & a_{8.8} & a_{8,9} \\
a_{9.1} & a_{9,2} & \cdots & \cdots & \cdots & a_{9.8} & a_{9,9}
\end{array}\right)
$$

Circuit parameter matrix $\mathbf{P}$ relating to parameters of state variables of state vector $\mathbf{x}(\mathrm{t})$ is defined as 


$$
\mathbf{P}=\left(\begin{array}{cccc}
\mathrm{C}_{f} & 0 & 0 & 0 \\
0 & \mathrm{C}_{0} & 0 & 0 \\
0 & 0 & \mathrm{~L}_{\mathrm{i}} & 0 \\
0 & 0 & 0 & \mathrm{~L}_{\mathrm{u}}
\end{array}\right)
$$

A of state equation (8) is obtained from $\mathbf{R}^{*}$ in eq.(15), $\mathbf{K}_{\mathbf{x}}$ in eq.(12) and $\mathbf{P}$ in eq.(16) as,

$$
A=P^{-1} \cdot \mathbf{R}^{*} \cdot K_{\mathbf{x}}
$$

$B$ of state equation (8) is obtained from $\mathbf{R}^{*}$ in eq.(15), $\mathbf{K}_{\mathbf{u}}$ in eq.(13) and $\mathbf{P}$ in eq.(16) as,

$$
\mathbf{B}=\mathbf{P}^{-1} \cdot \mathbf{R}^{*} \cdot \mathbf{K}_{\mathbf{u}}
$$

By the transformation process described above, all the elements of the matrices $\mathbf{A}$ and $\mathbf{B}$ of the state equation $(8)$ are obtained from the circuit equation. In simulation program, state vector $\mathbf{x}(\mathrm{t})$ is obtained from $\mathbf{A}$ and $\mathbf{B}$. $\mathbf{F}(\mathrm{t})$ is obtained from $\mathbf{x}(t)$ of previous state, $\mathbf{K}_{\mathbf{x}}, \mathbf{K}_{\mathbf{u}}$ and $\mathbf{u}(\mathrm{t})$. $\mathbf{G}(\mathrm{t})$ is obtained from eq.(14). Now $\mathbf{x}(\mathrm{t})$, together with $\mathbf{F}(\mathrm{t}), \mathbf{G}(\mathbf{t})$ and $\mathbf{R}$ gives us all the information of the converter circuit operation. From these calculated vectors, the simulated waveforms can be drawn for individual circuit parameters.

2.5 Simulation program steps Figure 4 illustrates simulation program steps to explain the simulation procedure.

Step-1: At the start point matrices $S(t), \mathbf{R}, \mathbf{R} *, \mathbf{P}, \mathbf{K}_{\mathbf{x}}, \mathbf{K}_{\mathbf{u}}, \mathbf{x}(\mathbf{t})$ and $\mathbf{u}(\mathrm{t})$ obtained from the circuit equations of switch modulated resistor circuit model are manually specified as input to main simulation program

Step-2: Transformation of circuit equation matrices to state equation matrices by simulation program to calculate $\mathbf{F}(\mathrm{t})$ from $K_{\mathbf{x}}, K_{\mathbf{w}}$ state vector $\mathbf{x}(\mathrm{t})$ and input vector $\mathbf{u}(\mathrm{t})$

Step-3: $\mathbf{G}(\mathbf{t})$ is estimated from $\mathbf{R}^{-1}$ and $\mathbf{F}(t)$.

Step-4: $\mathbf{R}$ is checked for change in switch state of $R_{S}$ and $R_{D}$. If there is a change in switch state of $R_{S}$ or $R_{D}$ the program again calculates the matrices of $\mathbf{R}, \mathbf{R}^{-1}, \mathbf{R}^{*}, \mathbf{A}$ and $\mathbf{B}$. The resistances $R_{S}$ and $R_{D}$ are decided from vector $R$ and real

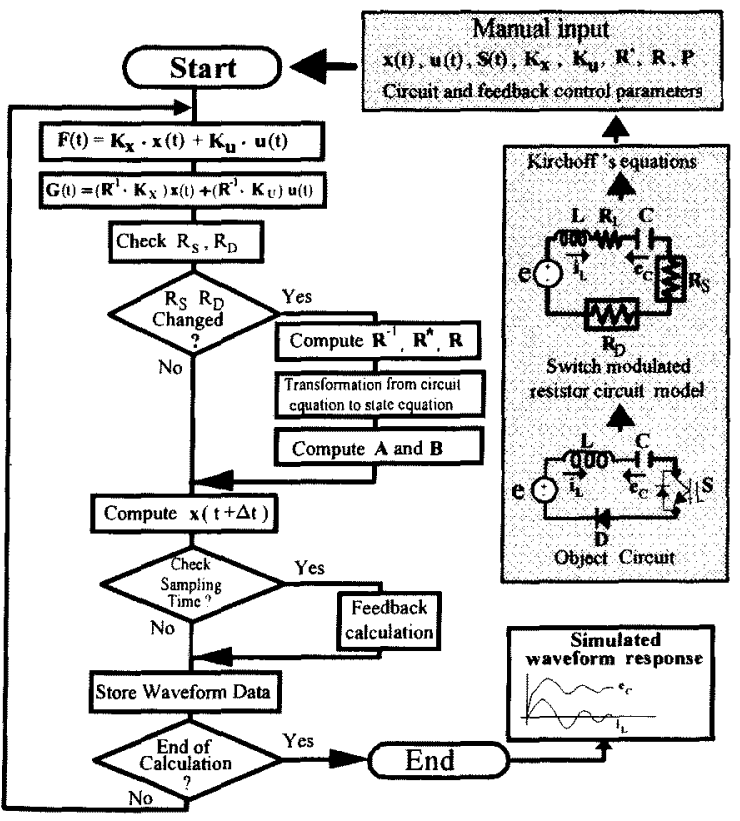

Fig.4 Schematic of simulation program steps time t. (see appendix for an example of computer source code of switch states)

Step-5: State vector $\mathbf{x}(t+\Delta t)$ for next calculation cycle is calculated by Runge-Kutta method.

Step-6: Control feedback calculation is done at the edges of simulation time step. Usually, it occurs once after 500 repetitions of calculation loop.

Step-7: When simulation calculations are completed, waveform data are written to data files, and waveforms are displayed on the computer monitor.

\section{Simulation of active Three Phase aC-DC CONVERTER SYSTEM}

3.1 Circuit model description Figure 5 illustrates a schematic diagram of active three phase voltage-fed AC-DC power converter system under $\mathrm{PFC}$ conversion conditioning and processing. Detecting signals of input line currents $\left(i_{z}, i_{y}, i_{x}\right)$ and output voltage $\mathrm{e}_{\mathrm{co}}$ the DSP control scheme produces PWM gate signals for modulating the pulse voltages across IGBTs, $S_{1}$ to $S_{6}$. By using this control scheme, unity power factor correction can be achieved under sine-wave current shaping, as well as a regulated DC output voltage.

3.2 Formulation of circuit and state equation In Figure 6 , the circuit network configuration of active three phase PFC power converter circuit is represented by simulation model using switch modulated resistors $R_{S 1}$ to $R_{S 6}$, which describe the active IGBT power switches $S_{1}$ to $S_{6}$. On-state and Off-state resistances for $R_{S 1}$ to $R_{S 6}$ are considered as an ideal switching condition with $R_{\text {on }}=10 \mathrm{~m} \Omega$ and $R_{\text {off }}=100 \mathrm{k} \Omega$. An auxiliary switch $R_{\text {So }}$ in series with load $R_{0}$ is suddenly turned on and off to investigate the circuit and system behaviour under load disturbance condition. The output waveform attains steady state in short time duration after the load disturbance is introduced. This can be observed in experiment as well as in simulation results.

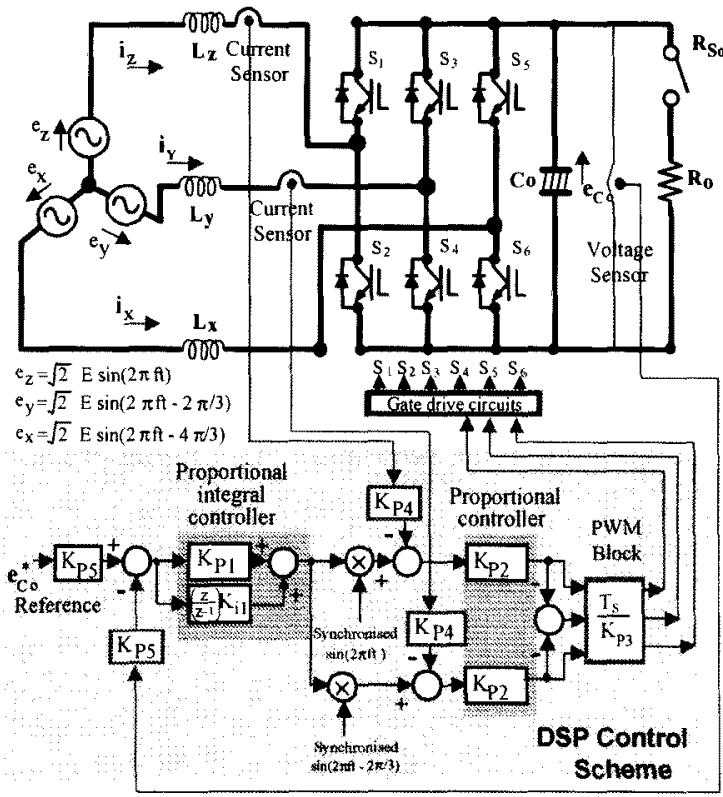

Fig.5 Active three-phase PFC converter circuit system with DSP control implementation 


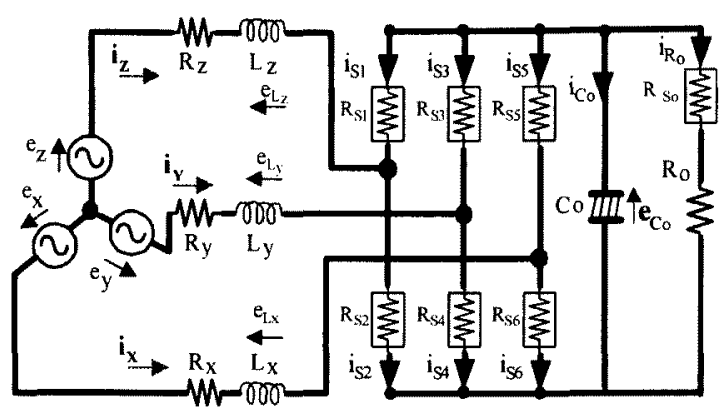

Fig.6 Formulation of simulation circuit model

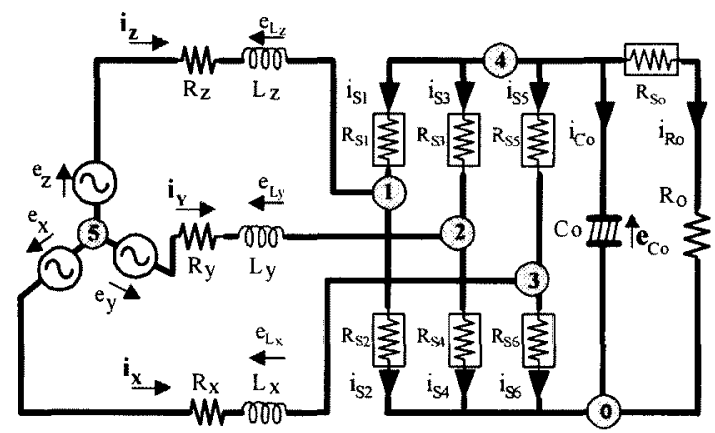

(a) Node diagram for $\mathrm{KCL}, \quad \mathrm{O}=$ Node

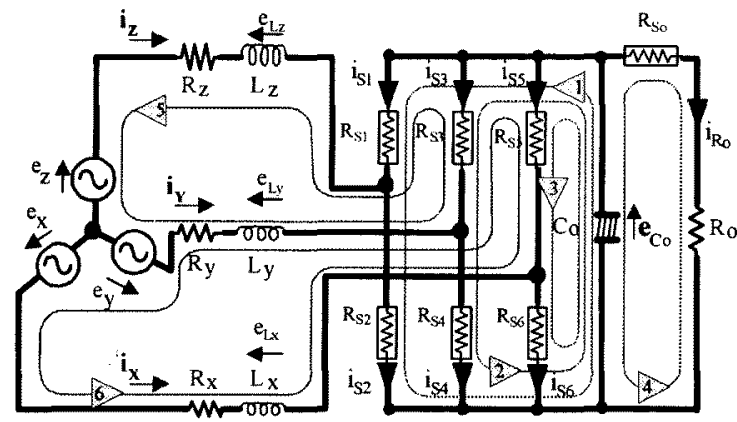

(b) Loop diagram for $\mathrm{KVL}, \quad D=$ Loop

Fig.7 Kirchoffs node and loop diagrams for circuit analysis

\begin{tabular}{|c|c|}
\hline Node 1 & $i_{z}=i_{S 2}-i_{S 1}$ \\
\hline Node 2 & $i_{y}=i_{S 4}-i_{S 3}$ \\
\hline Node 3 & $i_{x}=i_{56}-i_{55}$ \\
\hline Node 4 & $0=i_{S_{1}}+i_{S_{3}}+i_{S_{5}}+i_{R_{0}}+i_{C_{0}}$ \\
\hline Node 5 & $\mathrm{i}_{\mathrm{x}}+\mathrm{i}_{\mathrm{y}}+\mathrm{i}_{\mathrm{x}}=0$ \\
\hline Loop 1 & $\mathrm{e}_{\mathrm{Co}}=\mathrm{R}_{\mathrm{S} 1 .} \cdot \mathrm{i}_{\mathrm{S} 1}+\mathrm{R}_{\mathrm{S} 2 .} \mathrm{i}_{\mathrm{S} 2}$ \\
\hline Loop 2 & $e_{C_{0}}=R_{S 3 .} i_{S 3}+R_{S 4 .} i_{S 4}$ \\
\hline Loop 3 & 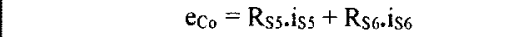 \\
\hline Loop 4 & $e_{C_{0}}=R_{0} \cdot j_{R_{0}}+R_{S_{0} .} i_{R_{0}}$ \\
\hline Loop 5 & 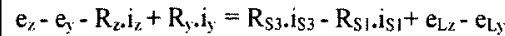 \\
\hline Loop 6 & $e_{x}-e_{x}-R_{Y} \cdot i_{Y}+R_{x} \cdot i_{x}=R_{S 5} . i_{S S}-R_{S 3} \cdot i_{S 3}+e_{L S}-e_{L x}$ \\
\hline
\end{tabular}

Applying the Kirchoff's laws; KVL and KCL to the circuit network, node and loop circuit diagrams are derived as shown in Fig.7. From node and loop diagrams, Kirchoff's equations in Table 2 are obtained. The state variables in this case are the voltage $e_{c o}$ across the capacitor and the phase currents $i_{z}, i_{y}, i_{x}$ through inductors. Input phase voltage variables are $e_{z}, e_{y}, e_{x}$. Relation between matrices $\mathbf{S}(t), \mathbf{N}(t)$ and $\mathbf{R}$ are obtained from Table 2. The non-state variable terms in $\mathbf{N}(\mathbf{t})$, whereas state variable terms in $\mathbf{S}(\mathfrak{t})$.

$$
\mathbf{S}(t)=\left(\begin{array}{c}
i_{z} \\
i_{y}^{y} \\
0 \\
i_{x}+i_{y}+i_{z} \\
e_{c_{o}} \\
e_{c_{o}}^{c_{o}} \\
e_{c o}^{c o} \\
e_{z}-e_{y}-R_{z} \cdot i_{z}+R_{y} \cdot i_{y} \\
e_{y}-e_{x}-R_{y} \cdot i_{y}+R_{x} \cdot i_{x}
\end{array}\right)
$$

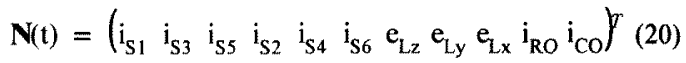

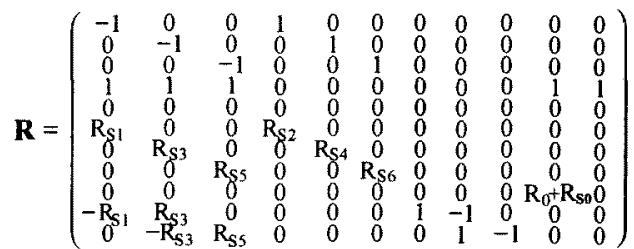

$\mathbf{R}^{-1}=\left(\begin{array}{cccccc}a_{1,1} & a_{1,2} & \cdots & a_{1,10} & a_{1,11} \\ a_{2,1} & a_{2,2} & \cdots & \cdots & a_{2,10} & a_{2,11} \\ \vdots & \vdots & \vdots & \vdots & \vdots & \vdots \\ \vdots & \vdots & \vdots & \vdots & \vdots & \vdots \\ a_{10,1} & a_{10,2} & \cdots & a_{10,10} & a_{10,11} \\ a_{11,1} & a_{11,2} & \cdots & \cdots & a_{11,10} & a_{11,11}\end{array}\right)$

where, $a_{i, j}=\frac{\text { adjoint } R_{i, j}}{|R|}(i=1,2,3 \ldots \ldots 11)$ and $(j=1,2,3 \ldots \ldots 1)$

The state vector $\mathbf{x}(t)$ containing state variables $\mathrm{e}_{c 0}$ for capacitors and $i_{z}, i_{y}, i_{x}$ for the inductors is expressed by

$$
\mathbf{x}(\mathbf{t})=\left(\begin{array}{llll}
\mathrm{i}_{\mathrm{z}} & \mathrm{i}_{\mathrm{y}} & \mathrm{i}_{\mathrm{x}} & \mathrm{e}_{\mathrm{C}_{\mathrm{e}}}
\end{array}\right)^{T}
$$

$\mathbf{P}, \mathbf{K}_{\mathbf{x}}, \mathbf{K}_{\mathbf{u}}, \mathbf{R}^{*}$ and $\mathbf{u}(\mathrm{t})$ are obtained according to procedure explained previously in section $\mathbf{2 . 4}$

$$
\begin{aligned}
\mathbf{P} & =\left(\begin{array}{cccc}
\mathrm{L}_{x} & 0 & 0 & 0 \\
0 & \mathrm{~L}_{\mathrm{y}} & 0 & 0 \\
0 & 0 & \mathrm{~L}_{\mathrm{x}} & 0 \\
0 & 0 & 0 & \mathrm{C}_{0}
\end{array}\right) \\
\mathbf{K} \mathbf{x} & =\left(\begin{array}{ccccccccccc}
1 & 0 & 0 & 0 & 1 & 0 & 0 & 0 & 0 & -\mathrm{R}_{\mathbf{z}} & 0 \\
0 & 1 & 0 & 0 & 1 & 0 & 0 & 0 & 0 & \mathrm{R}_{\mathrm{y}} & -\mathrm{R}_{\mathrm{y}} \\
0 & 0 & 1 & 0 & 1 & 0 & 0 & 0 & 0 & 0 & \mathrm{R}_{\mathbf{x}} \\
0 & 0 & 0 & 0 & 0 & 1 & 1 & 1 & 1 & 0 & 0
\end{array}\right)^{T}(25) \\
\mathbf{K}_{\mathbf{u}} & =\left(\begin{array}{ccccccccccc}
0 & 0 & 0 & 0 & 0 & 0 & 0 & 0 & 0 & 0 & -1 \\
0 & 0 & 0 & 0 & 0 & 0 & 0 & 0 & 0 & -1 & 1 \\
0 & 0 & 0 & 0 & 0 & 0 & 0 & 0 & 0 & 1 & 0
\end{array}\right)^{T}
\end{aligned}
$$




$$
\begin{aligned}
& \mathbf{R}^{*}=\left(\begin{array}{ccccccc}
a_{7,1} & \mathbf{a}_{7,2} & \cdots & \cdots & \cdots & \mathbf{a}_{7,10} & \mathbf{a}_{7,11} \\
\mathbf{a}_{8,1} & \mathbf{a}_{8,2} & \cdots & \cdots & \cdots & \mathbf{a}_{8,10} & \mathbf{a}_{8,11} \\
\mathbf{a}_{9,1} & \mathbf{a}_{9,2} & \cdots & \cdots & \cdots & \mathbf{a}_{9,10} & \mathbf{a}_{9,11} \\
\mathbf{a}_{11,1} & \mathbf{a}_{11,2} & \cdots & \cdots & \cdots & \mathbf{a}_{11,10} & \mathbf{a}_{11,11}
\end{array}\right) \\
& \mathbf{u}(\mathrm{t})=\left(\begin{array}{llll}
\mathrm{e}_{z} & \mathrm{e}_{\mathrm{y}} & \mathrm{e}_{\mathrm{x}}
\end{array}\right)^{T}
\end{aligned}
$$

where, $e_{z}=E_{m} \sin 2 \pi f t, e_{y}=E_{m} \sin (2 \pi f t-2 \pi / 3), e_{x}=E_{m} \sin (2 \pi f t-4 \pi / 3)$, and $E_{m}=\sqrt{2} E$. Formulations of eq. (19) to eq. (28) represent that for any type of power converter circuit, we need to develop matrices of $\mathbf{S}(t), \mathbf{R}, \mathbf{x}(\mathrm{t}), \mathbf{u}(\mathbf{t}), \mathbf{K}_{\mathrm{x}}, \mathbf{K}_{\mathbf{u}}, \mathbf{R}^{\mathrm{u}}$ and $\mathbf{P}$. Therefore, object-oriented programming concept is introduced in the simulation program design in order to conveniently modify and apply simulation program source code for a variety of power conversion circuit systems. Simulation program consists of 58 software modules. 39 modules out of these 58 modules can be applied to the other power converter circuits without any additional modifications. In the remaining 18 modules about half of the modifications consist of making simple changes in program statements instead of complex logic descriptions. Only those program statements need to be modified which contain $\mathbf{S}(\mathrm{t}), \mathbf{R}$, $\mathbf{x}(\mathrm{t}), \mathbf{u}(\mathrm{t}), \mathbf{K}_{\mathbf{x}}, \mathbf{K}_{\mathbf{u}}, \mathbf{R}^{*}, \mathbf{P}$, control algorithm, switching conditions and input/output functions.

\section{DSP CONTROL SCHEME}

4.1 Adaptability of control scheme The DSP system provides control signals to the practical power conversion conditioning circuit. Main merit of the proposed simulation is that the software code for control algorithm can be conveniently incorporated in the software of DSP based control system. In addition, the control parameter gain values used in simulation program are used to estimate the actual desirable control parameter gains of the PID controller present in DSP control system. Moreover, the state feedback control with feedback and feed-forward control loops, which is difficult to realize with the analog controller, can be easily implemented by this technique. As shown in Fig.8, the proportional-integral (PI) and proportional $(\mathrm{P})$ controllers prevent the fluctuations that affect the output response due to abrupt changes in utility $\mathrm{AC}$ power source side input line voltage and frequency. The output voltage of this active PFC power converter is digitally controlled and regulated under a PWM strategy ${ }^{(6)}$ for abrupt load changes. The modern control based digital processing scheme for active threephase converter system as depicted in Fig. 9 is basically the same as used in active single-phase PFC control scheme of Fig.8.

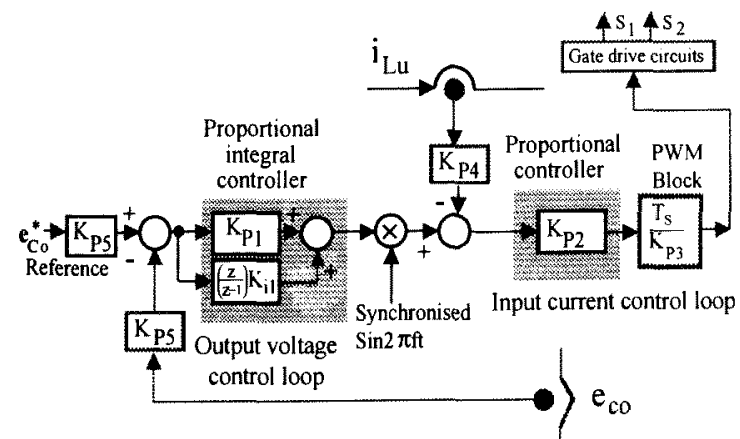

Fig.8 DSP control scheme of single phase PFC power converter system

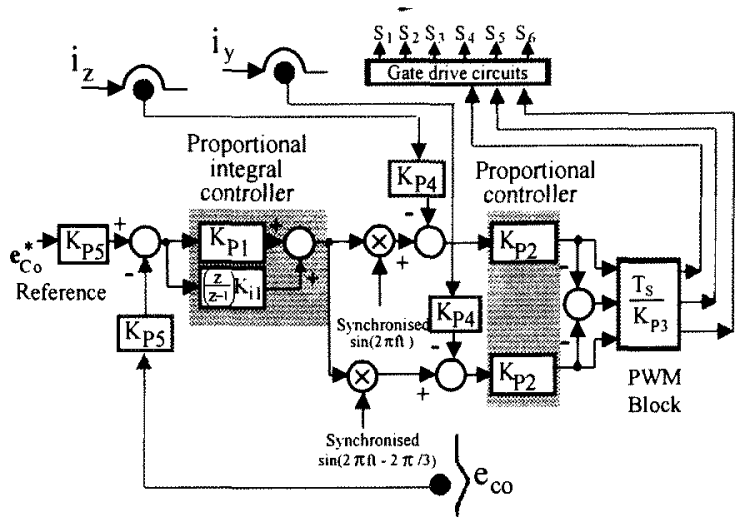

Fig.9 DSP control scheme of three phase PFC power converter system

4.2 Computer networking system for DSP controlled converter development A high speed server (UNIX) is dedicated to numerical computation. The various workstations, PCs, RISC processor development tools and printers are interconnected by a single computer network system. Therefore, documentation, programming and debugging for both the circuit simulation and DSP based control system can be achieved conveniently. By virtue of this simulation approach, the accurate results for active single-phase and three-phase converter systems discussed herein, can be obtained within 90 seconds for a $100-$ milisecond waveform on pentium-II, $400 \mathrm{MHz} \mathrm{CPU}$ computer.

\section{SIMULATION AND OBSERVED RESULTS}

5.1 Single phase AC-DC PFC converter system Tables 3 and 4 provide converter circuit design specifications and control parameter values used in simulation and practical design of a

TABLE 3. Circuit design specifications for single phase AC-DC PFC converter system

\begin{tabular}{c|l|cl}
\hline Symbol & Parameter & \multicolumn{2}{|c}{ Value } \\
\hline $\mathrm{e}$ & Input line voltage & 200 & $\mathrm{~V}_{\mathrm{rms}}$ \\
$\mathrm{f}$ & Input line frequency & $50 \mathrm{~Hz}$ \\
$\mathrm{R}_{\mathrm{Li}}$ & Input line resistance & 60 & $\mathrm{~m} \Omega$ \\
$\mathrm{R}_{\mathrm{Lu}}$ & Resistance & 50 & $\mathrm{~m} \Omega$ \\
$\mathrm{R}_{\mathrm{o}}$ & Load resistance & $13.2 \Omega$ \\
$\mathrm{L}_{\mathrm{i}}$ & Input line inductance & $60 \mu \mathrm{H}$ \\
$\mathrm{L}_{u}$ & Inductance & $185 \mu \mathrm{H}$ \\
$\mathrm{C}_{\mathrm{f}}$ & Input filter capacitance & $25 \mu \mathrm{F}$ \\
$\mathrm{C}_{\mathrm{o}}$ & Output filter capacitance & $5000 \mu \mathrm{F}$ \\
$\Delta \mathrm{d}_{\mathrm{l}}$ & Dead time of switch & $2.5 \mu \mathrm{s}$ \\
\hline
\end{tabular}

TABLE 4. Feedback control parameter values for single phase AC-DC PFC converter system

\begin{tabular}{c|l|c}
\hline Symbol & Parameter & Value \\
\hline $\mathrm{K}_{\mathrm{pl}}$ & Proportional controller gain V loop & 8 \\
$\mathrm{~K}_{\mathrm{p} 2}$ & Proportional controller gain I loop & 20 \\
$\mathrm{~K}_{\mathrm{p} 3}$ & Output voltage sensor coefficient & 1.024 \\
$\mathrm{~K}_{\mathrm{p} 4}$ & Input current sensor coefficient & 1.024 \\
$\mathrm{~K}_{\mathrm{p} 5}$ & Pulse width modulation coefficient & $16.0 \mathrm{e}^{-4}$ \\
$\mathrm{~K}_{\mathrm{i} 1}$ & Integral controller gain for I loop & 2 \\
$\mathrm{f}_{\mathrm{in}}$ & IGBT switching frequency & $15.6 \mathrm{kHz}$ \\
$\mathrm{e}_{\mathrm{Co}}$ & Reference output voltage & $650 \mathrm{~V}$ \\
$\mathrm{f}_{\text {inref }}$ & Reference input current frequency & $50 \mathrm{~Hz}$ \\
$\mathrm{~T}_{s}$ & Calculation time step & $0.5 \mu \mathrm{s}$ \\
\hline
\end{tabular}


single-phase PFC converter. Fig. 10 illustrates that the simulated waveform of input current $\mathrm{i}_{\mathrm{Lu}}$ has almost no phase difference with input voltage $\mathrm{e}_{\mathrm{Cr}}$ and is the same as the measured waveform shown in Fig.11.

Simulated output voltage response waveform illustrated in Fig. 12 has a good agreement with that measured as shown in Fig.13. Output voltage reaches steady state in extremely short time duration using proposed DSP based control scheme. Identical results from simulation and experimental observation validate the proposed simulation technique.

Figure 14 illustrates simulated $\mathrm{AC}$ line current with the proposed single-phase PFC converter connected to the utility power grid. High frequency switching of power devices operating under proposed DSP control scheme has a minimum distorting effect on the sinusoidal shape of utility line current.

In Fig.15, waveforms of modulated switch resistors $R_{S 1}$ and $R_{S 2}$ represent resistance condition $\mathrm{ON}(0)$ and $\mathrm{OFF}(1)$ of active IGBT power switches $S_{1}$ and $S_{2}$. When $S_{1}$ is $O N(0)$, current is $i_{S 1}$ flowing through $S_{1}$ begins to rise. When $S_{2}$ is ON(0), current $i_{S 2}$ flowing through $S_{2}$ begins to rise. Current $i_{L u}$ flowing through inductor $L_{u}$ is the resultant current $\left(i_{s_{2}}-i_{s_{1}}\right.$ ) flowing through active power switches $S_{1}$ and $S_{2}$. High frequency PWM ${ }^{(6)}$ switching action of power devices $S_{1}$ and $S_{2}$ produces resultant current $i_{L u}$ in Fig.15 drawn for $0.5 \mathrm{~ms}$ time period.

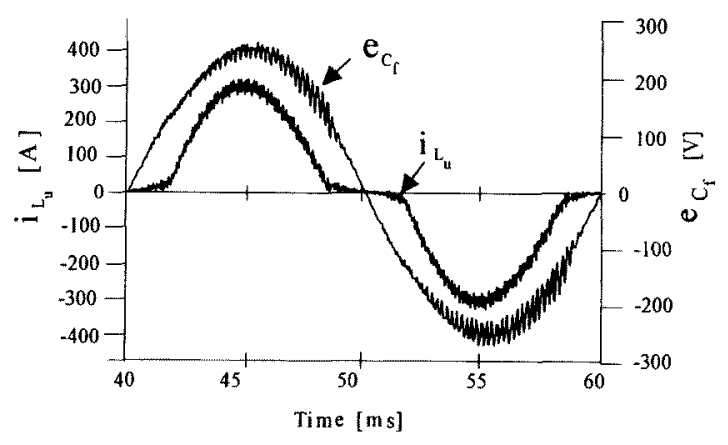

Fig.10 Simulated waveforms of single phase PFC converter

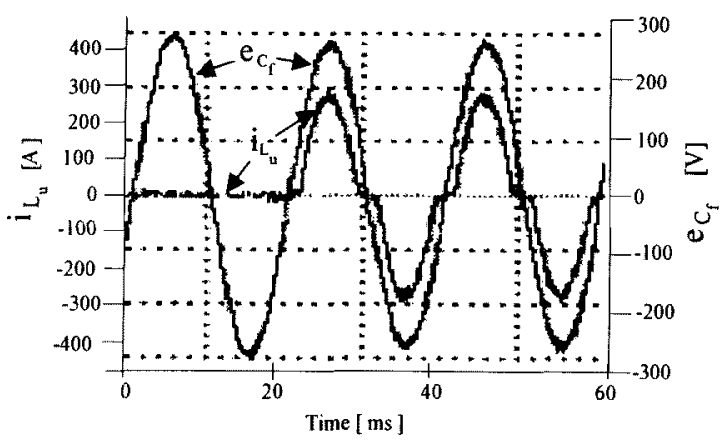

Fig.11 Measured voltage and current waveforms in AC utility side

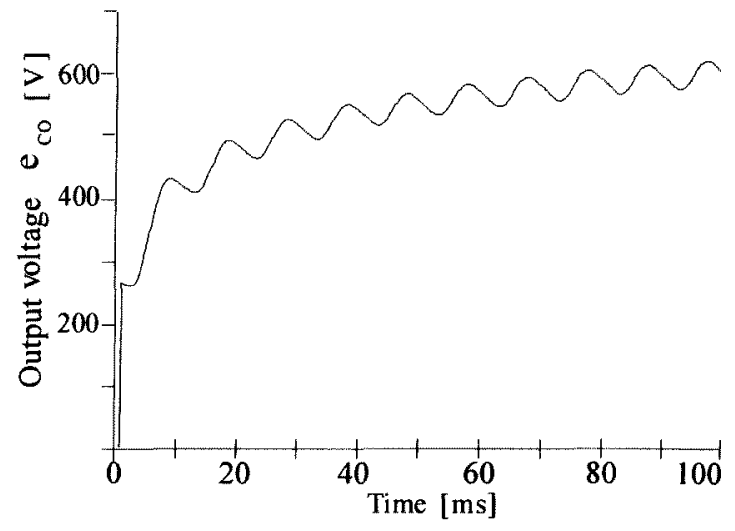

Fig.12 Simulated output voltage response in dynamic state

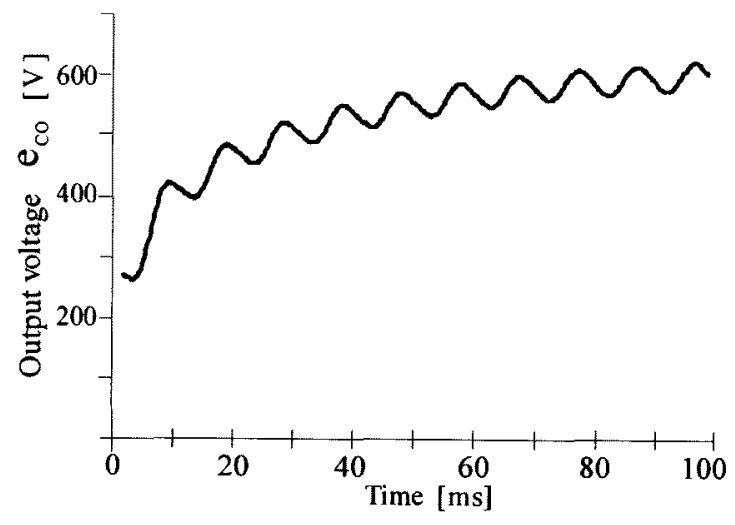

Fig.13 Measured output voltage response in dynamic state

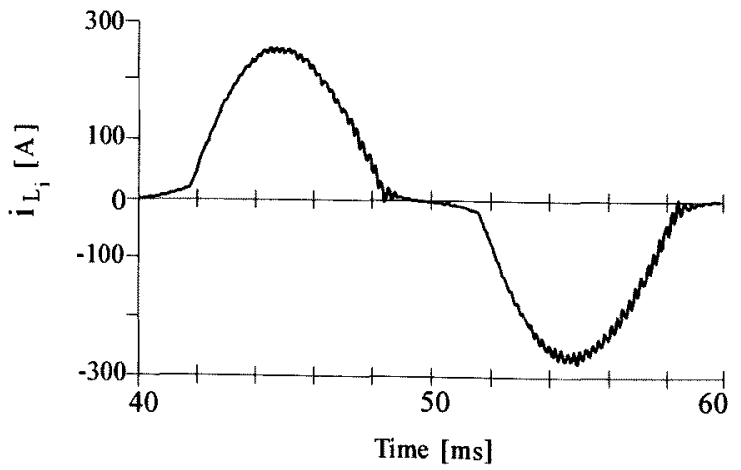

Fig.14 Simulated input current in AC utility side 

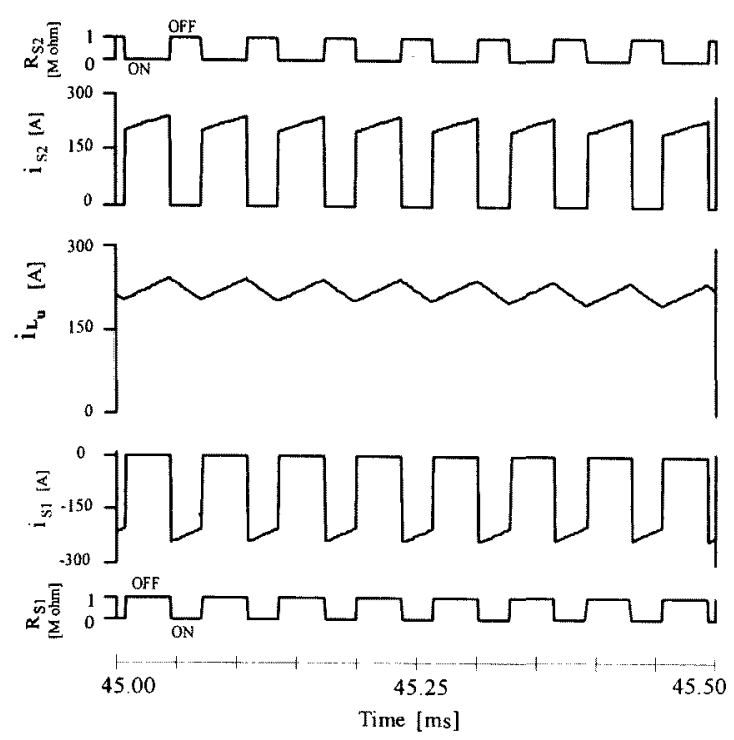

Fig. 15 Simulated switch and input currents

5.2 Three phase AC-DC PFC converter system Tables 5 and 6 provide circuit design specifications and control parameter values used in simulation and practical design of a three-phase PFC power converter system. Fig. 16 illustrates that the simulated waveforms of input phase current $\mathrm{i}_{\mathrm{X}}$ have almost no phase difference with input phase voltage $e_{X}$ and simulated waveforms are the same as measured waveforms shown in Fig.17.

Simulated output voltage waveform in Fig. 18 has a good agreement with the measured waveform as shown in Fig.19. Output voltage reaches steady state in extremely short time duration using proposed DSP based control system, when load disturbance is applied by turning off/on the auxiliary switch $R_{s o}$.

In Fig. 20, simulated waveforms of $R_{\mathrm{S}_{1}}$ and $R_{\mathrm{S} 2}$ represent model resistance condition $\mathrm{ON}(0)$ and $\mathrm{OFF}(1)$ of active IGBT power switches $S_{1}$ and $S_{2}$. Current $i_{z}$ flowing through inductor $L_{z}$ is the resultant current $\left(i_{s_{2}}-i_{S 1}\right)$ through active switches $S_{1}$ and $S_{2}$. High frequency PWM ${ }^{(6)}$ switching action of active power devices $S_{1}$ and $S_{2}$ produces fine shape of resultant current $i_{z}$ as shown in Fig.20.

The output voltage ripple consists of a low frequency ripple caused by the $\mathrm{AC}$ line frequency of voltage source and a high frequency ripple caused by switching frequency of the active switches of power converter. The high frequency ripple are concerned with the following reasons,

(i) Internal impedance effect (Equivalent Series Resistance: ESR and Equivalent Series Inductance: ESL) of the output smoothing filter capacitance.

TABLE 5. Circuit design specifications for active three

\begin{tabular}{c|l|cl}
\multicolumn{2}{c|}{ phase AC-DC PFC converter system } \\
\hline Symbol & Parameter & \multicolumn{2}{|c}{ Value } \\
\hline $\mathrm{e}_{\mathrm{z}}, \mathrm{e}_{\mathrm{y}}, \mathrm{e}_{\mathrm{x}}$ & Input phase voltage & $200 \mathrm{~V}$ \\
$\mathrm{f}$ & Input line frequency & $50 \mathrm{~Hz}$ \\
$\mathrm{R}_{\mathrm{z}}, \mathrm{R}_{\mathrm{y}}, \mathrm{R}_{\mathrm{x}}$ & Input line resistance & $12 \mathrm{~m} \Omega$ \\
$\mathrm{R}_{\mathrm{o}}$ & Load resistance & $1.9 \Omega$ \\
$\mathrm{L}_{\mathrm{z}}, \mathrm{L}_{\mathrm{y}}, \mathrm{L}_{\mathrm{x}}$ & Input line inductance & $150 \mu \mathrm{H}$ \\
$\mathrm{C}_{\mathrm{o}}$ & Output filter capacitance & $8200 \mu \mathrm{F}$ \\
$\Delta \mathrm{d}_{\mathrm{t}}$ & Dead time of switch & $2 \mu \mathrm{s}$ \\
\hline
\end{tabular}

TABLE 6. Feedback control parameter values for active

\begin{tabular}{c|l|l}
\multicolumn{3}{c}{ three phase AC-DC PFC converter system } \\
\hline Symbol & Parameter & Value \\
\hline $\mathrm{K}_{\mathrm{i}}$ & Integral controller gain V loop & 0.05 \\
$\mathrm{~K}_{\mathrm{pl}}$ & Proportional controller gain V loop & 0.62 \\
$\mathrm{~K}_{\mathrm{p} 2}$ & Proportional controller gain I loop & 0.62 \\
$\mathrm{~K}_{\mathrm{p} 3}$ & Pulse width modulation coefficient & 0.003 \\
$\mathrm{~K}_{\mathrm{p} 4}$ & Input current sensor coefficient & 1.02 \\
$\mathrm{~K}_{\mathrm{p} 5}$ & Output voltage sensor coefficient & 2.02 \\
$\mathrm{f}_{\mathrm{in}}$ & IGBT switching frequency & $15.6 \mathrm{~Hz}$ \\
$\mathrm{e}_{\mathrm{Co}}$ & Reference output voltage & $360 \mathrm{~V}$ \\
$\mathrm{f}_{\text {inrof }}$ & Reference input current frequency & $50 \mathrm{~Hz}$ \\
$\mathrm{~T}_{\mathrm{s}}$ & Calculation time step & $0.1 \mathrm{Hs}$ \\
\hline
\end{tabular}

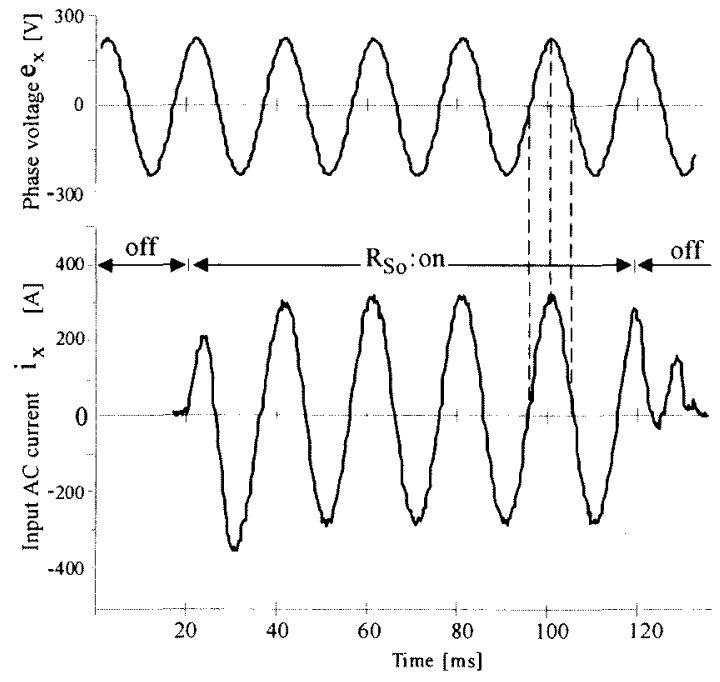

Fig.16 Simulated input voltage and current waveforms for a load disturbance

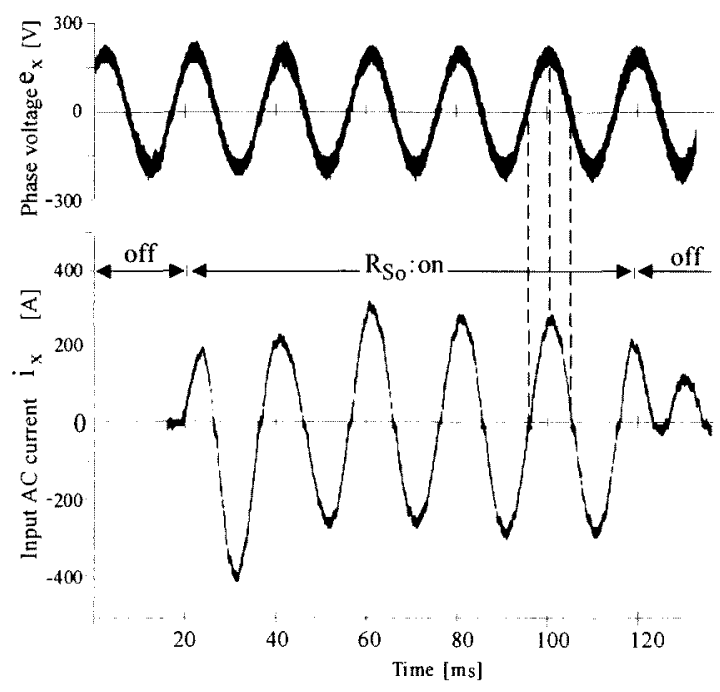

Fig.17 Measured input voltage and current waveforms for a load disturbance 


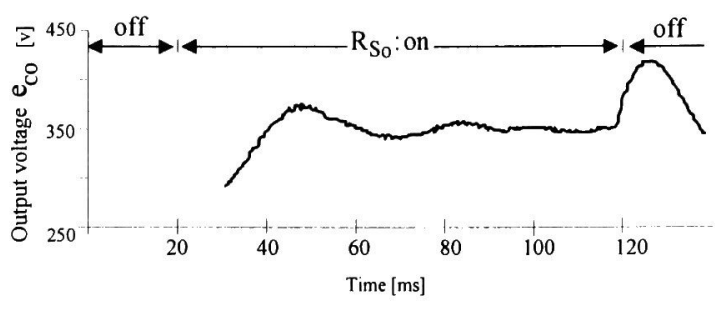

Fig.18 Simulated output voltage waveform for load disturbance

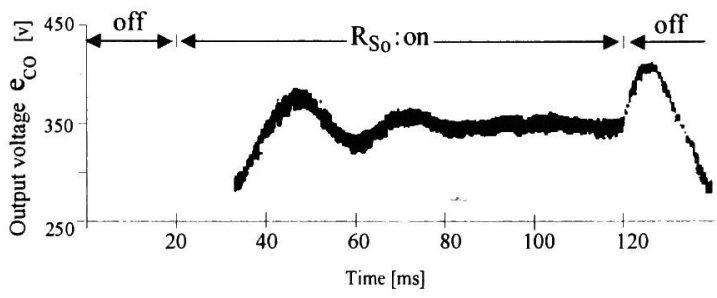

Fig. 19 Measured output voltage waveform for load disturbance
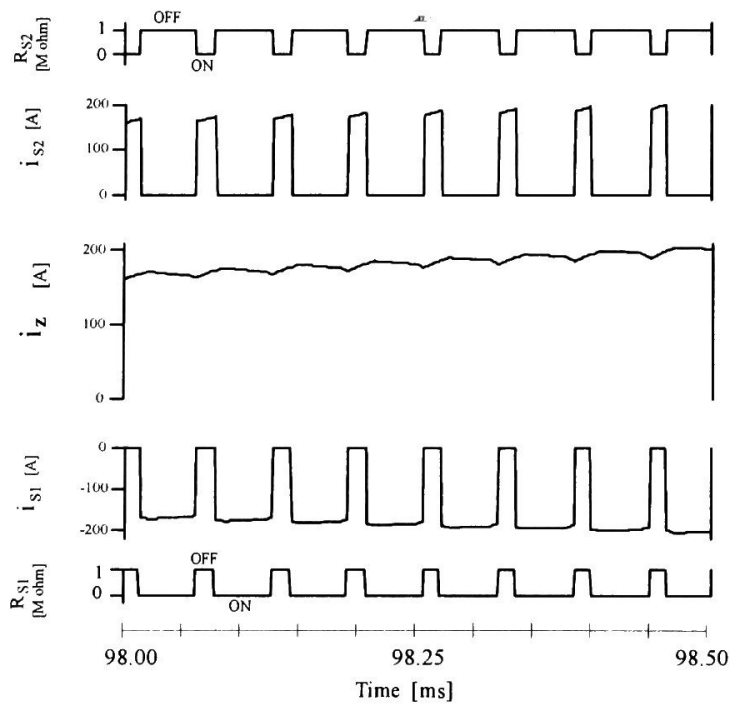

Fig.20 Simulated switch and input currents.

(ii) Leakage current effect caused by high $\mathrm{dv} / \mathrm{dt}$ value of the output line voltage of the AC-DC converter.

In experiment, the additional ripple caused by the ESR and ESL of the smoothing filter is about $5.0 \mathrm{~V}$. In simulation model, the ESR and ESL of the smoothing output filter capacitance is not considered. Consequently, the output voltage ripple is not significant in simulation results.

\section{CONCLUSIONS}

In this simulation approach, two DSP controlled switch-mode PFC rectifier topologies; single phase active PFC and three phase active PFC power converter circuits and systems has been demonstrated. This circuit simulation approach for power electronic system could simplify the software debugging process and design of DSP controlled power converter circuits and systems. The control algorithm in circuit simulation program could be easily incorporated into a DSP based practical power conversion conditioning circuit. The simulation, programming, debugging, documentation, mathematical computations and application of control algorithm to DSP controlled system have been achieved on a simple computer networking system (LAN). Furthermore, the proposed simulation technique has also been applied to some different types of switch-mode PWM DC-DC converters ${ }^{(7)(8)}$

In the future, a current-fed three phase PFC converter with a digital control scheme, active power filter and static varcompensator with digital control processing scheme as well as high frequency resonant inverters and converters with their related digital control schemes should be evaluated using this simple simulation technique.

(Manuscript received May 26, 1998; revised June 17, 1999)

\section{REFERENCES}

(1) G. D. Hachtel, R. K. Brayton, F. G. Gustavson: "The sparse tableau approach to network analysis and design", IEEE Trans. on Circuit Theory, Vol.CT-18-1, pp. 101-113, 1971.

(2) Y. Kuroe, H. Haneda and T. Maruhashi: "An efficient digital simulation program NETCAP-IM for power-electronic induction motor drive systems by means of decomposed tableau approach", Proc. of IEEE International Symposium on Circuits and Systems, Vol.II, pp. 704-707, April 1980.

(3) J. Burdio and A. Martinez: "A unified discrete-time state-space model for switching converters", IEEE Trans. on Power Electronics, Vol. 10-6, pp. 694-707, 1995.

(4) F. Witulski and R. Erickson: "Extension of state-space averaging to resonant switches and beyond", IEEE Trans. on Power Electronics, Vol. PE-5-1, pp. 98-109, January 1990

(5) Kato and W. Tachibana: "Periodic steady-state analysis by a modified shooting method for a power electronic circuit", Proc. of IEEJ Power Conversion Conference, Vol 1, pp. 367-372, August 1997

(6) K. Schultz : "An application of low cost hitachi SH-1 RISC controller for PID control of a three-phase brushless DC motor system", PMH11LA05D1 Hitachi America, Ltd., pp18-21, September, 1997. [http://semiconductor hitachi.com/products /h micon/1 sh/1 sh1/H11LA005D1/pdf/h1105.pdf]

(7) H. Takano, S. M. Ulhaq, and M. Nakaoka: "Efficient computeraided simulation approach of switched-mode power conversion circuits and systems with digital control implementation and its application", Proc. of IEEE Power Electronics Specialists Conference, Vol.1, pp. 908-915, June 1997

(8) S. M. Ulhaq, H. Takano, and M. Nakaoka: "State vector equation based computer simulation approach of digitally controlled power conversion circuits and systems", Proc. of IEEJ Power Conversion Conference, Vol.2, pp. 385-390, August 1997

\section{Ulhaqsyed MOBIN (Student Member)}

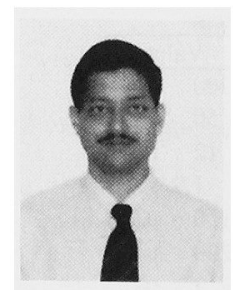

He was born in Lahore, Pakistan. He received B.E. in electrical engineering from national NED University, Karachi, Pakistan in 1988 He joined government power plant Corporation. $\mathrm{He}$ is a candidate in doctor of engineering course of division of electrical systems engineering, graduate school of science and engineering at Yamaguchi University. His research area is power electronics circuit and control system simulation and software developments. He is student member of IEE-J and IEEE-USA. 
Hiroshi TAKANO (Member)

He received the B. E. degree in 1981, and M. E. 月 degree in 1983 in production system engineering from Toyohashi University of Technology, Aichi, Japan. He is senior engineer at research and development center, Hitachi Medical Corporation, Japan. His interest areas are research and development of medical use highpower converter systems with digital control scheme and electro-mechanical systems engineering. He is a member of IEEE, IEE-J and Japan society of power electronics

Mutsuo NAKAOKA (Member)

$\mathrm{He}$ received D.E. degree in electrical engineering from Osaka University, Osaka, Japan. He worked as a professor in electrical and electronics engineering department, Kobe University, Kobe, Japan. He is now a professor and supervisor of power electronics control and systems engineering laboratory, graduate school of science and engineering at Yamaguchi University, Japan. His research interests include the state-of-art development of applied power electronic circuits and systems. $\mathrm{He}$ is a member of IEEE, IEE-J, IEICE-J, IEE-K, EPE and IEEUK

\section{APPENDIX}

The switch modulated resistors $R_{S}$ and $R_{D}$ are decided from $\mathbf{R}$ and real time t, by using simple program statements of "if...elseif..." style as shown in example given below.

/*****Simulation program source code example in C-Language for determining switch states of $\mathrm{R}_{\mathrm{S}}$ and $\mathrm{R}_{\mathrm{D}} * * * * *$ /

GetRsRd( double, long );

int GetRsRd( Duty, iNow )

double Duty;

long iNow,

\{

int $\quad \mathrm{i}$

long $\quad \mathrm{tt}, \mathrm{Rsl}, \mathrm{Rsh}$;

double $\quad$ rss[2];

$\mathrm{tt}=\mathrm{iNow} \%$ FreqCount;

if $((0<=\mathrm{tt}) \& \&(\mathrm{tt}<$ FreqCount $*$ Duty $/ 2))$

$\{\mathrm{rss}[1]=\mathrm{Rsl}$

$\operatorname{rss}[2]=R s h ;\}$

elseif $(($ FreqCount $*$ Duty $/ 2<=t \mathrm{t}) \& \&(\mathrm{tt}<($ FreqCount $*$ Duty $/ 2+$ Dead Time)) )

$\{\operatorname{rss}[1]=$ Rsh

$\operatorname{rss}[2]=$ Rsh; $\}$ 